\title{
PZT-PMN Ceramics for Large Displacement Piezoelectric Devices
}

\author{
Kee-Joe Lima and Jae-Yeol Park \\ School of Electrical and Computer Engineering, Chungbuk National University, Cheongju, \\ Chungbuk 361-763, Korea \\ Jong-Sub Lee \\ R\&D Center, EMD Co., Ltd. Ipjang Myun, Cheonan, Chungnam 363-792, Korea \\ Seong-Hwa Kang \\ Dept. of Industrial Safety Engineering, Chungcheong College, Gangnae-myeon, \\ Cheongwon-gun, Chungbuk 363-792, Korea \\ Hyun-Hoo Kim \\ Department of Electronics, Doowon College, Ansung, Gyeonggi 456-890, Korea \\ ${ }^{a}$ E-mail : kjlim@chungbuk.ac.kr
}

(Received February 20 2004, Accepted April 7 2004)

\begin{abstract}
Piezoelectric and dielectric properties as functions of $\mathrm{x}$ and $\mathrm{y}$ mole ratio in $\mathrm{yPb}(\mathrm{ZrxTi1}$ x) $\mathrm{O}_{3}(1-\mathrm{y}) \mathrm{Pb}\left(\mathrm{Mn}_{1 / 3} \mathrm{Nb}_{2 / 3}\right) \mathrm{O}_{3}$, ceramics, PZT-PMN, are investigated for large displacement piezoelectric devices. From the experimental results, when $\mathrm{y}$ is 0.95 and $\mathrm{x}$ is 0.505 , the piezoelectric and dielectric properties are maximum, that is, electromechanical coupling coefficient $(\mathrm{kp})$, piezoelectric strain constant $\left(\mathrm{d}_{33}\right)$, permittivity $\left(\varepsilon_{33} \mathrm{~T} / \varepsilon_{0}\right)$, and Curie temperature are $58 \%, 272 \mathrm{pC} / \mathrm{N}, 1520$ and about $350{ }^{\circ} \mathrm{C}$, respectively. Also, when $\mathrm{y}$ is 0.90 and $\mathrm{x}$ is 0.50 , their properties are $56 \%, 242 \mathrm{pC} / \mathrm{N}, 1220$, and $290{ }^{\circ} \mathrm{C}$, respectively. As $\mathrm{MgO}$ dopant is added from $0 \mathrm{wt} \%$ to $1 \mathrm{wt} \%, \mathrm{kp}$ increases to $63 \%$ and $\mathrm{Qm}$ decreases to 500 at the $\mathrm{MgO}$ dopant of $0.1 \mathrm{wt} \%$, and then $\mathrm{kp}$ decreases to $57 \%$ as $\mathrm{MgO}$ is added.
\end{abstract}

Keywords : Piezoelectric ceramic, Large displacement, Dielectric properties

\section{INTRODUCTION}

As MEMS and smart material technologies mature, the mobile communication systems are becoming more attractive. In applications such as mobile phone and pager, the need and method to supply their energy can be a significant engineering problem. Mobile phone and pager have used batteries to supply their energy. Batteries offer only a limited life span to a system. In recent, the rapid developments in integrated circuit technology of the type described by Moore's law have not been matched by similar advances in battery technology[1]. Thus, power requirements place important limits on the capability of mobile communication equipments. An alternative to batteries is to use the ambient energy that is available in the environment surrounding a system. Possible sources of the ambient energy include vibration, solar energy, and temperature difference, but the energy source using vibration may be in general. Accordingly, it is focused on micro generating system using piezoelectric ceramics. In order to apply to micro generating system, the important properties of piezoelectric ceramics for micro generating system are high electromechanical coupling coefficient, high piezoelectric strain constant and high permittivity. Piezoelectric ceramics that have these excellent piezoelectric and dielectric properties are lead zirconate titanate (PZT) based ternary piezoelectric ceramics. The ternary piezoelectric ceramics are used extensively for piezoelectric devices and are promising materials for large displacement actuator or electric generating devices. Compared with the binary solid solution ceramic system PZT, the ternary piezoelectric ceramics show desirable features[2,3]. In addition, the piezoelectric properties can be changed over a wide range by changing the composition and dopants[4-6]. 
PZT-PMN ceramic has higher piezoelectric activities and higher electro-mechanical coupling factor. It was well known that this ternary ceramic has high power characteristics.

In this paper, thepiezoelectric and dielectric properties of $\mathrm{Pb}(\mathrm{ZrxTi1}-\mathrm{x}) \mathrm{O}_{3} \mathrm{~Pb}\left(\mathrm{Mn}_{1 / 3} \mathrm{Nb}_{2 / 3}\right) \mathrm{O}_{3}$ ternary system are investigated for large displacement devices as functions of $\mathrm{Zr} / \mathrm{Ti}$ mole ratio, ternary composition mole ration and dopant. Also, X-ray diffractometer(XRD)and scanning electron microscopy(SEM) analysis are measured to find MPB and crystallization of the film, and observed microstructure as a function of sintering temperature to obtain transition temperature. DTA(dielectric temperature analysis) is also measured.

\section{EXPERIMENTAL}

The composition formula of ternary piezoelectric ceramic system is designed as following;

$$
\begin{gathered}
\mathrm{yPb}(\mathrm{ZrxTi1}-\mathrm{x}) \mathrm{O}_{3} \quad(1-\mathrm{y}) \mathrm{Pb}\left(\mathrm{Mn}_{1 / 3} \mathrm{Nb}_{2 / 3}\right) \mathrm{O}_{3}+ \\
\text { z[wt\%] } \mathrm{MgO}
\end{gathered}
$$

where, $0.49<\mathrm{x}<0.515, \mathrm{y}=0.9,0.95, \mathrm{z}=0 \sim 1 \mathrm{wt} \%$

The raw materials such as $\mathrm{PbO}, \mathrm{ZrO}_{2}, \mathrm{TiO}_{2}, \mathrm{MnCO}_{3}$, $\mathrm{Nb}_{2} \mathrm{O}_{5}$ and $\mathrm{MgO}$ of $99 \%$ purity were used for the given composition of the films. After these powders were weighed in appropriate proportions and mixed, they were calcined at $800{ }^{\circ} \mathrm{C}$ for $4 \mathrm{~h}$ in a magnesia-covered crucible. The calcined products were crushed and then ground by ball milling for $48 \mathrm{~h}$. The ground powder had a particle size ranging from 0.06 to $0.2 \mathrm{~m}$ with mean diameter of $0.15 \mathrm{~m}$. The ground powder was mixed with organic binder, and the granule was pressed. TGA(thermal gravitation analysis) is measured to determine the burn-out temperature of binder[7].

Figure 1 shows a result of the measured TGA. As the temperature increases, its gravitation critically decreases because water and organic binder contained in it are evaporated. Therefore, the pressed body was kept at $450{ }^{\circ} \mathrm{C}$ for $6 \mathrm{~h}$ to burn out the organic binder, and then was sintered in a magnesia-covered crucible from $1100{ }^{\circ} \mathrm{C}$ to $1250{ }^{\circ} \mathrm{C}$ for $2 \mathrm{~h}$ in $\mathrm{PbO}$ atmosphere. The samples were metallized by printing Ag paste and firing at $590{ }^{\circ} \mathrm{C}$ and the specimens were poled under the electric field of $2.5 \mathrm{kV} / \mathrm{mm}$ for $30 \mathrm{~min}$. in silicon oil of $120{ }^{\circ} \mathrm{C}$

Piezoelectric strain constant $(\mathrm{d} 33)$ is measured by Berlincourt $d_{33}$-meter(CHANNEL product), and other dielectric and piezoelectric constants are measured by impedance analyzer (HP4194A) and calculated using resonance-antiresonance method by IRE Standard. The crystal structure was analyzed by $\mathrm{X}$-ray diffraction pattern in the range of $2 \theta$ using $\mathrm{Cu}-\mathrm{K} \alpha\left(\lambda=5.406{ }^{\circ} \mathrm{C}\right)$ (SCINTAG product).

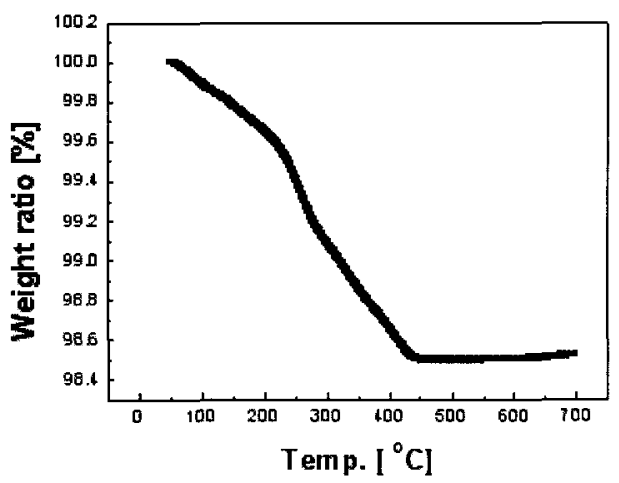

Fig. 1. Thermal gravitation analysis.

\section{RESULTS AND DISCUSSION}

\subsection{Micro structure observed by SEM}

Figure 2 shows the photographs of micro-structure with the sintering temperature by SEM. As shown in Fig. 2 , the grain is not completely grown at $1100^{\circ} \mathrm{C}$. As the sintering temperature increases, the grain size becomes large as well as the pores also increase gradually. Accordingly, from Fig. 2, optimal sintering temperature is $1150{ }^{\circ} \mathrm{C}$ in these piezoelectric ceramics.

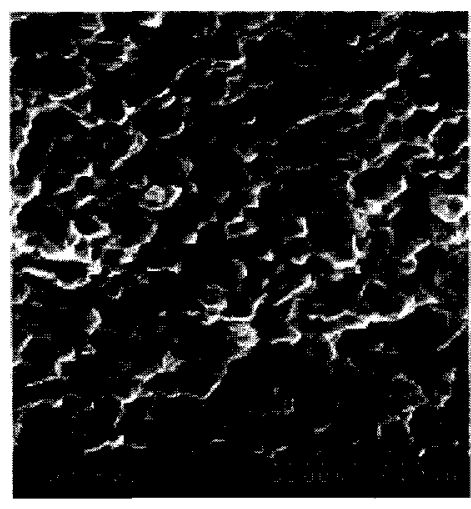

(a) $1100{ }^{\circ} \mathrm{C}$

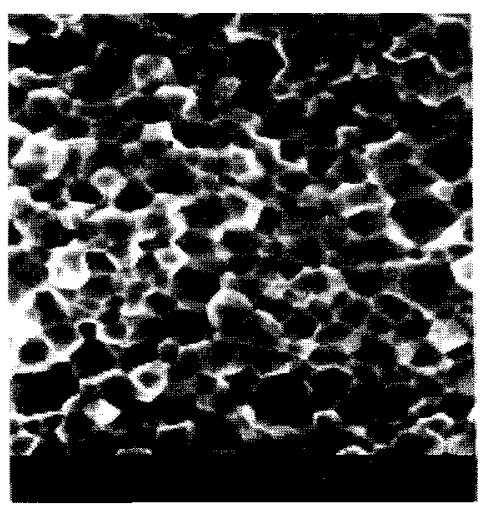

(b) $1150{ }^{\circ} \mathrm{C}$ 


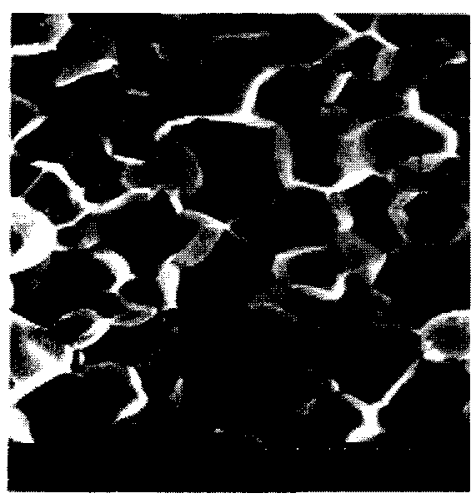

(c) $1200{ }^{\circ} \mathrm{C}$

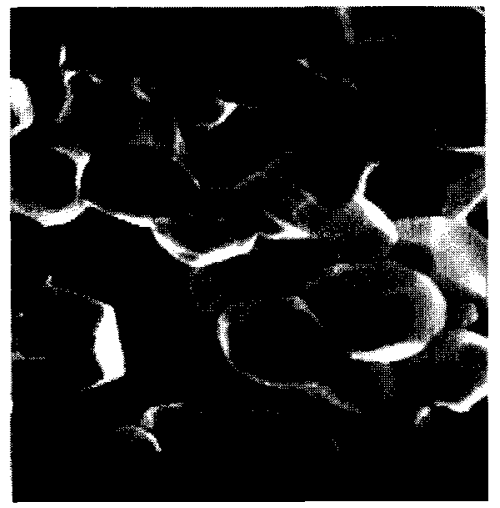

(d) $1250{ }^{\circ} \mathrm{C}$

Fig. 2. The micro structure of ceramic specimen according to sintering temperature.

\subsection{Phase analysis by XRD}

The typical XRD patterns of $0.95 \mathrm{~Pb}(\mathrm{ZrxTi1}-\mathrm{x})$ $\mathrm{O}_{3} 0.05 \mathrm{~Pb}\left(\mathrm{Mn}_{1 / 3} \mathrm{Nb}_{2 / 3}\right) \mathrm{O}_{3}$ piezoelectric ceramics sintered at $1150{ }^{\circ} \mathrm{C}$ as a function of $\mathrm{x}$ are shown in Fig. 3.

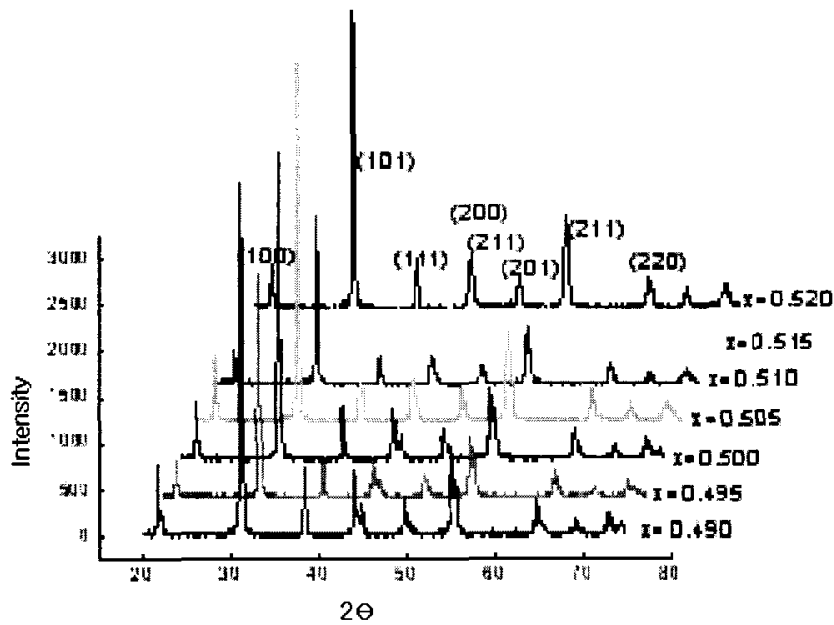

Fig. 3. XRD patterns as a function of $\mathrm{x}$ in $0.95 \mathrm{~Pb}$ ( $\mathrm{ZrxTi1}-\mathrm{x}) \mathrm{O}_{3}-0.05 \mathrm{~Pb}\left(\mathrm{Mn}_{1 / 3} \mathrm{Nb}_{2 / 3}\right) \mathrm{O}_{3}$ ceramics.

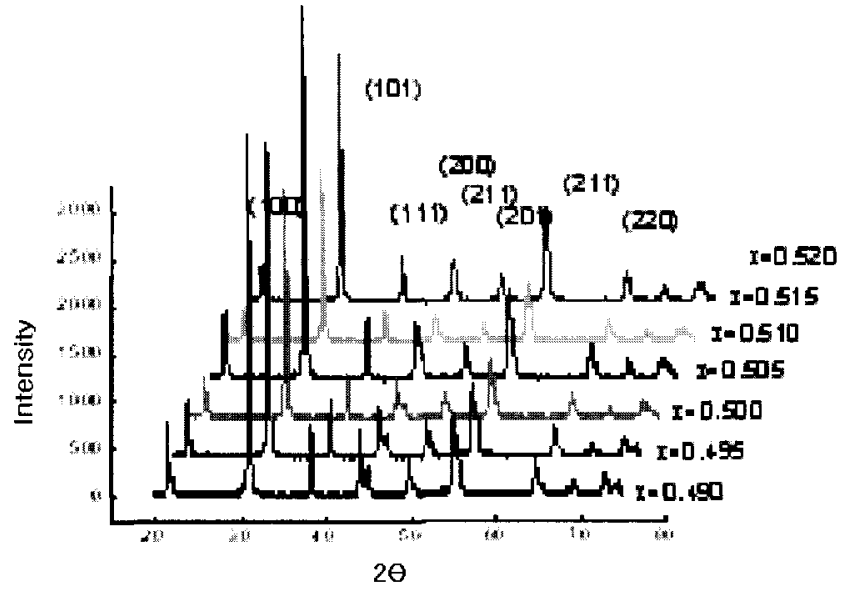

Fig. 4. XRD patterns as a function of $\mathrm{x}$ in 0.9Pb (ZrxTi1x) $\mathrm{O}_{3}-0.1 \mathrm{~Pb}\left(\mathrm{Mn}_{1 / 3} \mathrm{Nb}_{2 / 3}\right) \mathrm{O}_{3}$ ceramics.

The figure shows the typical perovskite phase of PZTPMN film without secondary phase such as a pyrochlore phase. It also indicates that $\mathrm{x} \leq 0.50$ results in tetragonal phase. On the other hand, rhombohedral phase is dominant at $\mathrm{x} 0.51$ as revealed by disappearance of the splitting of the (200) and (211) peaks.

In this ternary system, the morphotropic phase boundary (MPB) assumes to be $x=0.505$, which coexists both ferroelectric phases. The XRD patterns of $0.9 \mathrm{~Pb}(\mathrm{ZrxTi}-\mathrm{x}) \mathrm{O}_{3} 0.1 \mathrm{~Pb}\left(\mathrm{Mn}_{1 / 3} \mathrm{Nb}_{2 / 3}\right) \mathrm{O}_{3}$ ceramics are shown in Fig. 4. From these results, the MPB assumes to be $x=0.50$. Comparing with pure $P Z T$, it seems that the MPB of PZT-PMN ceramics shifts slightly to Ti-rich composition.

\subsection{Piezoelectric and dielectric properties}

The changes of electromechanical coupling coefficient (kp), piezoelectric strain constant $\left(\mathrm{d}_{33}\right)$, mechanical quality factor $(\mathrm{Qm})$ and permittivity $\left(\varepsilon_{33}{ }^{\mathrm{T}} / \varepsilon_{0}\right)[8]$ as functions of $\mathrm{x}$ and $\mathrm{y}$ in $\mathrm{yPb}(\mathrm{ZrxTil}-\mathrm{x}) \mathrm{O}_{3}(1-\mathrm{y}) \mathrm{Pb}\left(\mathrm{Mn}_{1 / 3}\right.$ $\left.\mathrm{Nb}_{2 / 3}\right) \mathrm{O}_{3}$ ceramics are shown in Fig. 5 to 8 .

As shown in Figs. 5, 6 and 8, these factors increase gradually to maximum point with the increasing $x$ mole ratio, and then decrease after the maximum point. When $y$ is 0.95 and $x$ is 0.505 , each maximum value of $\mathrm{kp}, \mathrm{d}_{33}$ and $\varepsilon_{33}{ }^{\mathrm{T}} / \varepsilon_{0}$ is $58 \%, 272 \mathrm{pC} / \mathrm{N}$, and 1520 , respectively. Also, when $\mathrm{y}$ is 0.90 and $\mathrm{x}$ is 0.50 , each $\mathrm{kp}, \mathrm{d}_{33}$ and $\varepsilon_{33}{ }^{\mathrm{T}} / \varepsilon_{0}$ value is $56 \%, 248 \mathrm{pC} / \mathrm{N}$, and 1140 , respectively.

From Fig. 7, a minimum value of mechanical quality factor is 1550 at $\mathrm{y}=0.05$ and $\mathrm{x}=0.505$, and 1820 at $\mathrm{y}=0.1$ and $\mathrm{x}=0.50$, respectively. From these results, when $\mathrm{y}$ is 0.95 and $x$ is 0.505 or $y$ is 0.90 and $x$ is 0.50 , the MPB is appeared in PZT-PMN ternary piezoelectric ceramic system, and is shifted to Ti-rich, compared with the MPB in pure PZT, which is generally known. As mole ratio of 
ternary composition increases, the piezoelectric and lielectric properties decrease. Accordingly, in order to apply to large displacement devices, $0.95 \mathrm{~Pb}\left(\mathrm{Zr}_{0.505}\right.$ $\left.\cdot \mathrm{i}_{0.495}\right) \mathrm{O} 30.05 \mathrm{~Pb}\left(\mathrm{Mn}_{1 / 3} \mathrm{Nb}_{2 / 3}\right) \mathrm{O}_{3}$ ceramic system is available.

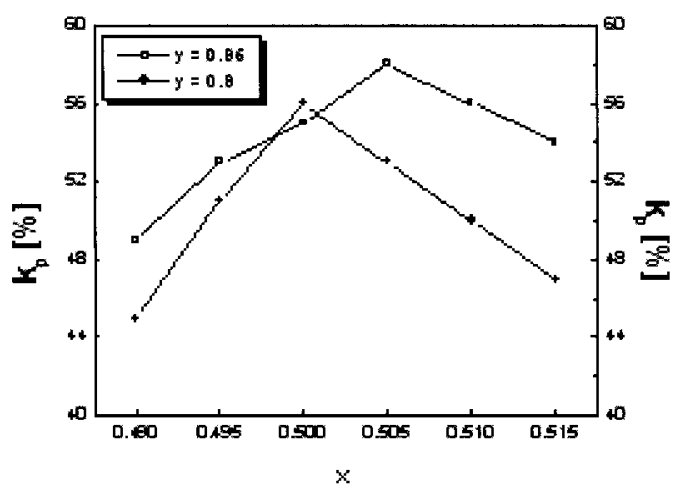

Fig. 5. Changes of $\mathrm{kp}$ as a function of $\mathrm{x}$ mole.

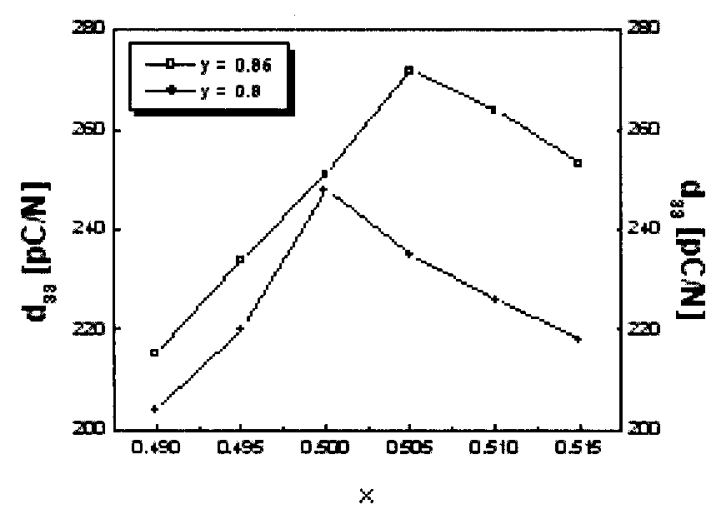

7ig. 6. The changes of $d_{33}$ as a function of $x$ mole.

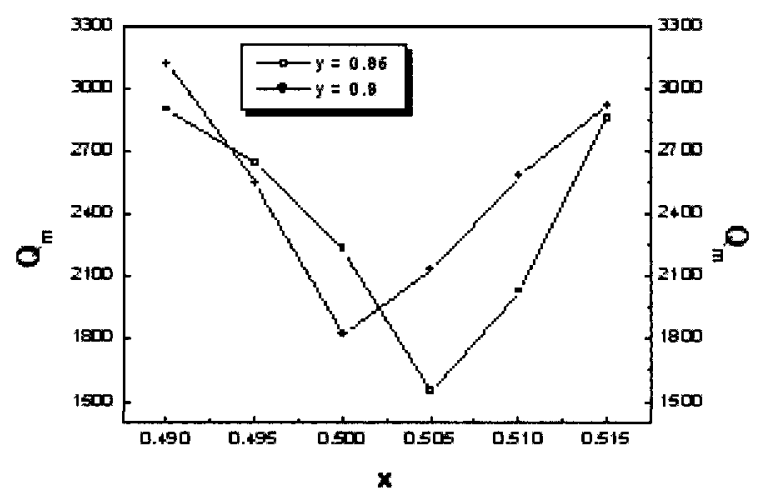

liig. 7. The change of $\mathrm{Qm}$ as a function of $\mathrm{x}$ mole .

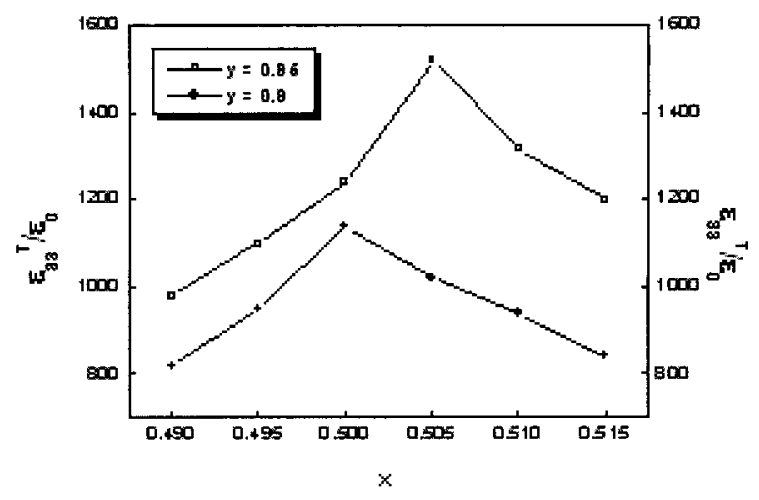

Fig. 8. The changes of $\varepsilon_{33}{ }^{\mathrm{T}} / \varepsilon_{0}$ as a function of $\mathrm{x}$ mole.

Figure 9 shows the relation between permittivity and temperature, which is measured by DTA. It indicates that Curie temperature may be around $350{ }^{\circ} \mathrm{C}$ for y of 0.95 and $290{ }^{\circ} \mathrm{C}$ for y of 0.9 , respectively.

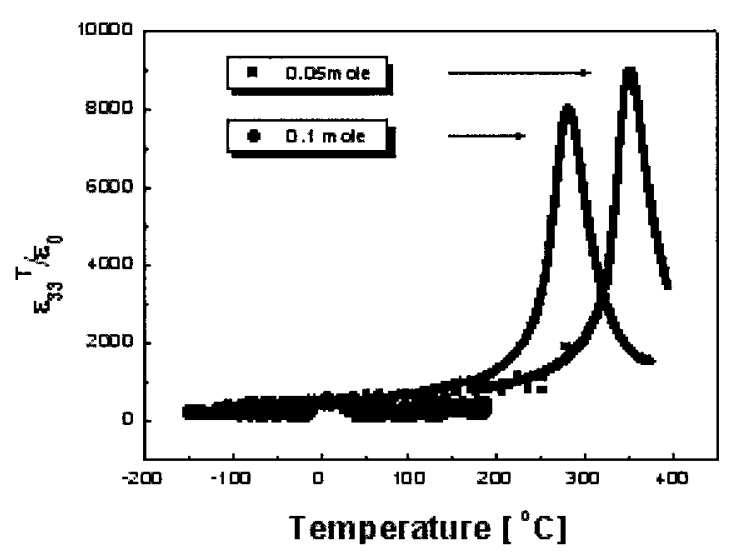

Fig. 9. Phase transition temperature.

\subsection{Dopant effect}

The profiles of $\mathrm{kp}$ and $\mathrm{Qm}$ as a function of the amount of $\mathrm{MgO}$ added in the ternary composition of $0.95 \mathrm{~Pb}\left(\mathrm{Zr}_{0.505} \mathrm{Ti}_{0.495}\right) \mathrm{O} 30.05 \mathrm{~Pb}\left(\mathrm{Mn}_{1 / 3} \mathrm{Nb}_{2 / 3}\right) \mathrm{O}_{3}$ are shown in Fig. 10. The amount range of $\mathrm{MgO}$ is from 0 to $1 \mathrm{wt} \%$. When the amount of $\mathrm{MgO}$ is $0.1 \mathrm{wt} \%$, $\mathrm{kp}$ increases to $63 \%$, but Qmdecreases to 500. As the amount of $\mathrm{MgO}$ increases to $1 \mathrm{wt} \%$, kpdecreases gradually and, however, $\mathrm{Qm}$ increases as shown in the figure.

Chen, et. al.[9] reported that the positive ion of dopant reacted with $\mathrm{Pb}^{2+}$ ion and then the dopant made the stable pyrochlore phase. As a result, the grain size becomes small. It is believed that the $\mathrm{Mg}^{2+}$ ions are substituted to B-site rather than A-site in the perovskite lattice at $\mathrm{MgO}$ dopant of $0.1 \mathrm{wt} \%$, resulting in the generation of oxygen vacancies in the structure. The oxygen vacancies directly contribute to the strinkage of the lattice and the dielectric properties are lowered. 
However, as the grain size becomes small with increasing dopants after $0.1 \mathrm{wt} \%$, the electromechanical coupling coefficient lowers and mechanical quality factor increases.

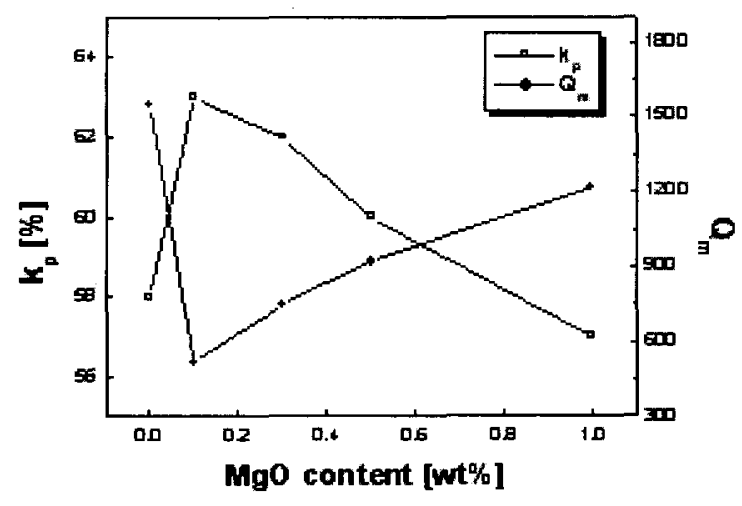

Fig. 10. The changes of $\mathrm{kp}$ and $\mathrm{Qm}$ as a function of the amount of $\mathrm{MgO}$.

\section{CONCLUSIONS}

In summary, the piezoelectric and dielectric properties as functions of $\mathrm{x}$ and $\mathrm{y}$ in $\mathrm{yPb}(\operatorname{ZrxTi} 1-\mathrm{x}) \mathrm{O}_{3}(1-\mathrm{y}) \mathrm{Pb}$ $\left(\mathrm{Mn}_{1 / 3} \mathrm{Nb}_{2 / 3}\right) \mathrm{O}_{3}$ piezoelectric ceramics are studied for large displacement devices. When $\mathrm{y}$ is 0.95 and $\mathrm{x}$ is 0.505 , the piezoelectric and dielectric properties of the ternary piezoelectric ceramic have the best values as follows: electromechanical coupling coefficient(kp), piezoelectric strain constant $\left(\mathrm{d}_{33}\right)$, permittivity $\left(\varepsilon_{33}{ }^{\mathrm{T}} / \varepsilon_{0}\right)$, and Curie temperature are $58 \%, 272 \mathrm{pC} / \mathrm{N}, 1520$ and about $350{ }^{\circ} \mathrm{C}$, respectively. Also, when $\mathrm{y}$ is 0.9 and $\mathrm{x}$ is 0.50 , its properties, $\mathrm{kp}, \mathrm{d} 33, \varepsilon_{33} \mathrm{~T} / \varepsilon_{0}$, and Curie temperature are $56 \%, 248 \mathrm{pC} / \mathrm{N}, 1140,290{ }^{\circ} \mathrm{C}$, respectively.

Also, as $\mathrm{MgO}$ is added from $0 \mathrm{wt} \%$ to $1 \mathrm{wt} \%$, kpincreases to $63 \%$ and $\mathrm{Qm}$ decreases to 500 at 0.1 wt $\% \mathrm{MgO}$, and then $\mathrm{kp}$ decreases, and $\mathrm{Qm}$ increases slightly until $1 \mathrm{wt} \%$ of $\mathrm{MgO}$. The superior properties in $0.95 \mathrm{~Pb}\left(\mathrm{Zr}_{0.505} \mathrm{Ti}_{0.495}\right) \mathrm{O}_{3} 0-.05 \mathrm{~Pb}\left(\mathrm{Mn}_{1 / 3} \mathrm{Nb}_{2 / 3}\right) \mathrm{O}_{3} \quad 0.1$ wt $\%$ $\mathrm{MgO}$ ceramic is shown. It is concluded that this piezoelectric ceramic can be a useful material for large displacement piezoelectric devices.

\section{ACKNOWLEDGEMENT}

This work has been supported by EESRI(R-2002-B035), which is funded by MOCIE(Ministry of commerce, industry and energy).

\section{REFERENCES}

[1] Koc, B., Alkoy, S., and Uchino, K., "A circular piezoelectric transformer with crescent shape input electrodes", 1999 IEEE ultrasonic symposium, p. 931. 1999.

[2] Sung-Jin Choi, Kyu-Chan Lee and Cho, B., "Design of fluorescent lamp ballast with PFC using a power piezoelectric transformer", 1998 IEEE ultrasonic symposium, p. 1135, 1998.

[3] Jin-Hong Chung, Seung-Min Lee, Mike Myung-Ok Lee, and Yang-Ho Moon, "High power 30W and high efficiency $80 \%$ piezoelectric transformer for EB", AP-ASIC '99, p. 131, 1999.

[4] Y. Yamashita and N. Ichinose, "Can relaxor piezoelectric materials outperform PZT?(Review)", 1996 Ultrasonic symposium, p. 71, 1996.

[5] Takahashi, S., and Hirose, S., "Vibration-level characteristics for iron-doped lead-zirconate-titanate ceramic", Jpn J. Appl. Phy. Vol. 32, No. 5B, p. 2422, 1993.

[6] Takahashi, S., Hirose, S., Uchino, K., and Ki-Young Oh, "Electro-mechanical characteristics of lead-zirconatetitanate ceramics under vibration-level chang", ISAF '94 Proc. Of the Ninth IEEE, p. 377, 1994.

[7] J. K. Hong, J. S. Lee, H. I. Chae, M. S. Yoon, S. H. Jeong, and K. J. Lim, "Characteristics of Piezoelectric and Dielectric of PMWN-PZT Ceramics" J. of KIEEME, Vol. 14, No. 6, p. 455, 2001.

[8] Y. J. Go, H. C. Kim, H. D. Nam, H. G. Chang, and H. Woo, "Design of the Piezoelectric Sounder Using the PMN-PT-PZ", J. of KIEEME, Vol. 14, No. 1, p. 12, 2001.

[9] J. C. Chen and G. W. Gui, "Modification of Piezoelectric Characteristics of the $\mathrm{Pb}(\mathrm{Mg}, \mathrm{Nb}) \mathrm{O} 3$ PbZrO3-PbTiO3 Ternary System by Aliovalent Additives", Journal of American Ceramic Society, Vol. 78, No. 1, p. 178, 1995. 